\title{
Vad har värdegrundsfrågor med engelskundervisningen att göra?
}

\author{
Av Anna Thyberg, doktorand i engelska med didaktisk inriktning, \\ Växjö universitet
}

Länk till presentation av Anna Thyberg

\section{Inledning}

I Sverige har det länge funnits en tydlig skiljelinje mellan ämnesdidaktik och allmändidaktik. Ämnesdidaktiken har koncentrerat sig på inlärningen av olika moment utan att kanske närmare analysera målen i relation till övergripande utbildningssträvanden. Allmändidaktiken å andra sidan har behandlat generella aspekter på inlärning såsom värdegrundsfrågor och demokratifostran men har förbigått det som skiljer inlärning av olika ämnen åt. För lärare ute i verksamheten går det förstås inte att separera ämnesdidaktik från allmändidaktik. I undervisningssituationen måste läraren samtidigt beakta exempelvis språkinlärningsstrategier och värdegrundsfrågor (anteckningar från föreläsning av professor Christer Fritzell 2003).

I dagens mångkulturella klassrum samsas elever från olika etniska grupper. På fritiden överöses eleverna av intryck från globaliserade massmedier, populärkultur och Internet. Allt detta innebär ständiga kulturmöten. Ofta är det först när vi konfronteras med andra kulturella yttringar som vi blir medvetna om vår egen kulturella hemvist. Men vilka funderingar och vilken världsbild informationsflödet skapar hos eleverna vet vi ganska lite om. Vi vet inte heller i vilken mån den demokratiska värdegrunden påverkas av denna globalisering.

Enligt socialfilosofin strävar varje individ efter att sammanjämka intrycken från livsvärlden (det vi bär med oss och tar för givet) med kunskapen om systemvärlden (samhällsstrukturerna), alltså att förstå omvärlden, sin plats i tillvaron och sig själv. Frågan är om skolan på något sätt kan hjälpa eleven på vägen mot denna förståelse. I detta sammanhang är det främst engelskundervisningens roll som intresserar mig. Detta tänker jag återkomma till nedan. Låt mig dock först ta upp definitionerna av några centrala begrepp till diskussion.

\section{Vad menas med kulturmöten?}

Definitionen av kultur är synnerligen komplex och användes tidigare mest frekvent inom antropologin. I dag kan kulturbegreppet vara oerhört vitt, som allt i ett samhälle, allt människor gör och tänker, men också snävt, t.ex. sociala koder på en arbetsplats. Normativa värderingar kan läggas på begreppet när man skiljer högt från lågt, t.ex. Virginia Woolf från Barbara Cartland. I dess sociologiska mening hänger identitet, tolkning, representativitet och makt nära samman med kultur. Därför får kulturen konsekvenser för hur mänskliga relationer konstrueras, främst i avgränsningar mellan "vi" och "dem". Det kan också ske i form av maktstrukturer som avgör vems tolkning av beteende eller språkbruk som anses gälla. En viktig aspekt av kulturfenomenet är alltså att i förhållande till den egna normen ses allt annat som avvikande. En bärare av detta avvikande betraktas i regel också som representativ för hela gruppen och som någon man måste lära sig att förstå. 
Enligt den antropologiska traditionen har västerlänningar tenderat att definiera kultur som något människor från andra världsdelar karaktäriseras av, medan de själva står för det universella och besitter en högre stående civilisation. Detta fokus på skillnader härrör sig från att kulturbegreppet skapas i konfrontation. Medvetet eller omedvetet kan människor resonera inte bara i termer som "Vad är det som skiljer?" utan också "Vad kan vi göra så att skillnaden består?". Det är lätt att förledas att tro att kultur är något som i relativt oförändrad form traderas över generationerna eller följer nationella gränser, men så är inte fallet. Kulturer är likt processer dynamiska och de omskapas kontinuerligt i anpassning till nya strömningar. Däremot kan förändringsbenägenheten minska i en situation av migration där kulturen för en grupp blir det enda kvarvarande bandet till hemlandet.

Vad är då ett möte, är det helt självklart? Inte nödvändigtvis, man kan t.ex. hävda att ett möte förutsätter någon form av förändring. Ett möte där parterna inte förmår kommunicera blir då ett icke-möte. Även läsandet av en text, betraktandet av en bild eller en film utgör ett möte. Vilket syfte individen har med mötet skiftar naturligtvis. Tonvikten kan ligga på ett ömsesidigt utbyte av erfarenheter och kunskap eller på ett försvarsinriktat framhävande av egna intressen. Filter av stereotyper och negativa förväntningar som läggs på motpartens handlingar och uttalanden försvårar givetvis kommunikationen i mycket hög grad, oberoende av om det handlar om en grupp av människor eller en ensam läsare.

\section{Vad är syftet med värdegrundsfrågor?}

Vad kan vi då göra för att hjälpa eleverna att skapa mening och struktur i den fragmentariska tillvaro som jag skisserade ovan? Jo, i undervisningen skulle vi kunna ge dem tillfälle att diskutera problem av allmänmänsklig karaktär. Eleverna kan få vända och vrida på moraliska dilemman i samarbete och dialog med andra. Intressanta frågor kan vara: Vad innebär det egentligen att vara människa? Vad skiljer oss åt och vad är gemensamt? Vilka moraliska måttstockar används för att skapa normer och värderingar? Hur kan man tillämpa ideal som jämlikhet, rättvisa och solidaritet i praktiken? På vilket sätt är kulturmöten ett problematiskt begrepp? Vilka historiskt grundade föreställningar bär vi med oss?

Det är den här typen av frågor som jag skulle vilja klassificera som värdegrundsfrågor. Genom att arbeta med dem i skolan är förhoppningen att eleverna får lättare att förhålla sig till influenser i största allmänhet. Jag vill också klargöra att skolans uppdrag att fostra inte måste ses som en slags indoktrinering av eleverna. Det kan snarare betraktas som ett incitament för att använda demokratiska arbetssätt. Eleverna försätts i situationer där de i ett frigörande, s.k. deliberativt, samtal lär sig att respektera andra människor. Ett sådant samtal förutsätter att eleverna får möjlighet att ta ställning till olika åsikter och värderingar samt att reflektera över varför de tycker som de gör. Detta arbetssätt blir därmed en del av den demokratiska fostran som läroplanen sätter upp som mål. Eleven får förbereda sig för ett aktivt medborgarskap i en demokrati.

Värdegrundsfrågor skulle alltså kunna sägas handla om förhållningssätt till omvärlden och om mänskliga relationer. Men man skulle också kunna påstå att värdegrundsfrågor utgör basen i all pedagogisk verksamhet eftersom de bestämmer hur vi ser på kunskap och vilken funktion utbildningen får. Likaså kan inte pedagogisk praktik särskiljas från värdegrundsfrågor, hur och med vad vi arbetar i skolan präglas av vår människosyn och vår definition av kunskap.

\section{Koppling mellan läroplanen och ämnet}

Ovannämnda värdegrundsfrågor må vara nog så intressanta, men har de egentligen några beröringspunkter med mitt intresseområde, engelskämnet? Låt mig ta upp två argument som stödjer tesen att värdegrundsfrågor bör beaktas i engelskundervisningen, dels står det i läroplanen att demokratiska värderingar ska prägla all undervisning (Skolverket, Läroplan för de frivilliga skolformerna 1994: 5), dels har språkundervisningen naturliga 
förutsättningar att erbjuda en lämplig arena. Engelskundervisningen ger i sig upphov till kulturmöten, vilka i sin tur kan aktualisera värdegrundsfrågor, dessutom har eleverna uppnått ganska goda språkkunskaper på gymnasiet, och därför anser jag att det finns en möjlighet att utveckla en litteraturundervisning med kulturmöten i centrum. Det skulle kunna leda till en integration av värdegrundsperspektivet i engelskämnet. För övrigt omfattar kärnämneskurser relativt många timmar, vilket är gynnsamt när det handlar om att arbeta med attityder och värderingar.

I läroplanen har den svenska regeringen och riksdagen gett uttryck för vad man definierar som värdegrunden, nämligen:

\begin{abstract}
Människolivets okränkbarhet, individens frihet och integritet, alla människors lika värde, jämställdhet mellan kvinnor och män samt solidaritet med svaga och utsatta är de värden som skolan skall gestalta och förmedla. I överensstämmelse med den etik som förvaltats av kristen tradition och västerländsk humanism sker detta genom individens fostran till rättskänsla, generositet, tolerans och ansvarstagande. (Skolverket, Läroplan för de frivilliga skolformerna 1994: 5)
\end{abstract}

Trots att det är relativt universella värden som uttrycks refererar man uttryckligen till kristna traditioner och västerländsk humanism. Eftersom skolan har som mål att fostra eleverna i tolerans, jämlikhet och solidaritet med andra människor samt utveckla interkulturell förståelse kan man tycka att eleverna borde få möta andra kulturer i sin undervisning. Ett kulturmöte kan dock te sig på olika vis. Många skolor har internationellt utbyte men ändå kan man inte räkna med att alla elever får chansen att deltaga i det. De etniska grupper som finns representerade i klassen kan visserligen berika samtal om kulturella fenomen, men det är viktigt att inte låta individen representera en hel grupp.

I engelskundervisningen kan litteraturen bli mötesplatsen för olika kulturer. Känsliga frågor blir lättare att diskutera när eleven kan använda litterära karaktärer som ställföreträdare. Dessutom menar forskare som Louise Rosenblatt att elever kan träna upp sin empatiska förmåga genom att läsa skönlitteratur, vilket skulle göra dem mer mottagliga för andra människors sinnesstämningar och bättre på att upptäcka bakomliggande orsaker till mänskliga handlingar etc. Kort sagt får eleverna lättare att förstå mänskliga relationer (Rosenblatt 1995: 49).

Även i betygskriterierna för engelska B uttrycks en koppling mellan kultur och litteratur: "Eleven beskriver olika samhällsförhållanden, kulturtraditioner och levnadssätt i områden där engelska talas, och använder denna bakgrund för att kommentera och diskutera skönlitteratur..." (Skolverket 2000b).

Eftersom inlärning är en livslång process är det också viktigt att ge eleverna förutsättningar att fortsätta språkinlärningen efter det att den formella undervisningen är avslutad, vilket också uttrycks i kursplanen. Visserligen hör eleverna mycket engelska genom musik, på bio och tv, men de behöver också möta språket i skrift. Det kan de förstås göra i form av Internettexter och tidningar, men läsning av skönlitteratur innehåller något mer. Först och främst ger litteratur en estetisk upplevelse men också ingående skildringar av målspråkskulturerna, något som korta hypertexter inte kan erbjuda. Därmed kan eleverna lättare nå en ökad grad av interkulturell förståelse, vilket numera har ersatt tidigare kursplansskrivningar om realiakunskap. Så här uttrycks det i mål att sträva mot i ämnet engelska: "[eleven] reflekterar över levnadssätt, kulturtraditioner och samhällsförhållanden i engelskspråkiga länder samt utvecklar fördjupad förståelse och tolerans för andra människor och kulturer" och i Skolverkets fortsatta presentation av ämnet på samma hemsida: "Förmågan att reflektera över likheter och skillnader mellan egna kulturella erfarenheter och kulturer i engelsktalande länder utvecklas hela tiden och leder på sikt till förståelse för olika kulturer och interkulturell kompetens" (Skolverket 2000a). Kulturmöten blir därmed ett naturligt blickfång i läsningen av skönlitterära texter inom engelskämnet.

Med anledning av följande skrivning i kursplanen: "Utbildningen i engelska har dessutom som syfte att vidga perspektiven på en växande engelsktalande omvärld med dess 
mångskiftande kulturer" (Skolverket 2000a) finns grund för en utökning av läsningen så att texter från andra engelsktalande områden än England och USA ingår. Här kan alltså postkoloniala texter komma in, vilka på senare år rönt stort intresse inom

litteraturvetenskaplig forskning. Postkolonialismen har visserligen blivit ett forskningsfält på modet, men också omdebatterat både till innehåll och begreppsbildning. En del forskare hävdar att postkolonialismen tog sin början redan vid den första kolonisationen medan andra menar att starten ägde rum först efter koloniernas frigörelse. Vanligtvis betraktas litteratur skriven på kolonialspråket av författare med ursprung i de forna kolonierna som postkolonial (Ashcroft m.fl. 1995: 117). Centrala teman i postkolonialismen är motstånd mot koloniala strukturer, representativitet, hybriditet, nationalism och etnicitet. Läsning av postkoloniala texter i klassrummet skulle kunna ge en inblick i engelskans kulturella mångfald och nuvarande ställning som världsspråk. Engelska språkets historiska bakgrund och olika regionala varianters status är inte okontroversiella. Studiet och diskussionen av litteratur kan öka elevernas medvetenhet om språkets splittrade kontext och om olika faktorer som orsakat detta. För att inte tala om fördelen med att eleverna genom litteraturen i någon mån får gemensamma referensramar med målspråkstalare, vilket i sin tur säkert underlättar interkulturell kommunikation.

\section{Synen på inlärning och kunskap}

Hur skulle man kunna arbeta för att uppnå inlärningsmålet i Läroplan för de frivilliga skolformerna, 1994, om värdegrundsfrågor? Går det över huvud taget att lära ut tolerans? Och hur skulle man gå till väga i så fall? För övrigt är det skillnad mellan tolerans och interkulturell kompetens, varav det förra nämns i läroplan för de frivilliga skolformerna, 1994 och det senare i kursplan för engelska 2000. Tolerans implicerar egentligen endast en acceptans för något avvikande. Det behöver inte innebära att man vill lära sig mer om andra kulturer eller integrera dem i sin livsvärld. Interkulturalitet är förmågan att gå mellan olika kulturer och att där interagera på lika villkor, samt ett öppet förhållningssätt och empati för andra människor och kulturer (Gudykunst \& Kim 1992: 253).

Återigen handlar det om vilken kunskapssyn man har. Både det sociokulturella och det fenomenografiska perspektivet på kunskap innebär att inlärning sker i samtal med andra människor, även om det senare fokuserar innehållet mer än interaktionen. I båda fallen konstrueras kunskapen i samtalet. Med dessa perspektiv organiseras undervisningen med fokus på kommunikation och skapande av dialogsituationer som möjliggör inlärning. Tror man i stället, liksom konstruktivisterna, att individen skapar sin kunskap i en inre process av tolkning och meningsskapande gäller det att utgå från elevens föreställningar i undervisningen för att kunna utmana och utveckla tänkandet.

\section{Värdegrundsfrågor omsatta i praktiken}

I läroplanen refereras det redan i första meningen till skollagen (1985:1100): "verksamheten i skolan skall utformas i överensstämmelse med grundläggande demokratiska värderingar" (1 kap. 2 och $9 \S \S$ ). Det är alltså viktigt att välja metoder och arbetssätt i skolan som i sig ger eleverna demokratisk övning. Men det är ingen framkomlig väg att helt sonika lämna alla beslut till eleverna. Det handlar i stället om att ge eleverna demokratiska redskap och att gradvis skola in eleverna i att ta ansvar för sin inlärning.

Christer Fritzell menar i sin artikel "Pedagogical Split Vision" (1996) att eftersom utbildning syftar till utveckling och förändring kan inte pedagogiska relationer mellan lärare och elev ses som entydigt instrumentella. Det handlar därmed inte om att förmedla ett kunskapsinnehåll från en hjärna till en annan. Alla relationer innehåller värderingar och uttrycker förväntningar. Fritzell anser att skolverksamheten bör syfta till att utveckla symmetri i pedagogiska relationer. Symmetri i detta sammanhang kan ses som en strävan efter jämlikhet i det meningsskapande som sker i inlärningssituationen, men också som det närmande som sker mellan lärare och elev när läraren utgår från elevens föreställningar och 
kunskapsnivå för att underlätta kommunikation kring ett kunskapsinnehåll.

Det är lärarens uppgift att uppnå individualisering genom att kunna motivera all inlärning som eleverna förväntas ta sig an. Enligt Fritzells synsätt skapas alltså symmetrin av pedagogen. Det är pedagogens ansvar att respektera elevens integritet och rättighet att deltaga i interaktionen på lika villkor. Habermas idé om det ideala samtalet kan, enligt Fritzell, relateras till diskussionen om det symmetriska samtalet eftersom båda bygger på att parterna deltager på lika villkor. Det är viktigt att individen får utrymme att argumentera för sina åsikter och att rätten att säga nej upprätthålls. I stället för att oreflekterat hamna i en mekanisk inlärning av lösryckta fakta i ett asymmetriskt (kunskapsförmedlande) system kan vi eftersträva ett konsekvent genomförande av symmetri i relationer och strukturer i skolan så att demokratiska värden blir synliggjorda och realiserade i praktiken (Fritzell 1996: 209-16).

Rosenblatt betonar att i ett demokratiskt arbetssätt lär sig elever efterhand att lyssna uppmärksamt till varandra, att respektera varandras åsikter och att se läraren som en i gruppen och inte som den viktigaste mottagaren. I samtalet om litteratur kan alltså förmågan till empati tränas (Rosenblatt 1995: 68).

Enligt Fritzells och Rosenblatts resonemang kan värdegrundsfrågor realiseras i den pedagogiska arbetsformen. Genom att betona demokratiska samtal i skolan lär sig eleverna inte bara ett kunskapsinnehåll utan även ett sätt att relatera till andra människor. Med ökad kunskap och erfarenhet blir andra människor och kulturer mindre hotfulla och lättare att förhålla sig till. Det är ju ofta genom att utmåla fienden som omänsklig som våld och konflikter rättfärdigas. Nu i tider av krig känns strävan efter empati ännu mer angelägen eftersom varje ny generation har till uppgift att erövra och skapa sin version av det demokratiska samhället. I det perspektivet skulle strävan mot interkulturalitet kunna generera bättre livskvalitet för eleverna och ge dem frihet att röra sig i en globaliserad värld.

\section{Utbildning i ett vidare perspektiv}

Bildningsidealet, som den svenska skolan vilar på och där värdegrundsbegreppet ingår, innebär att elever ska ges möjlighet att utvecklas som människor, inte bara tillägna sig kunskap. Eleverna går i skolan för att vidga sitt tänkande och möta andra föreställningar än de som finns i den närmaste omgivningen och i hemmet. I detta ligger också fostransaspekten: stimulerandet av kritiskt tänkande och de färdigheter som behövs i ett demokratiskt samhälle. När elever upplever läsglädje och utvecklas genom litteraturläsning nås också ett större mål i undervisningen eftersom hela människan, både rationella och irrationella sidor får utrymme i undervisningen. Kan läsglädjen och respekten för personliga ställningstaganden komma i centrum kan detta i bästa fall leda till att ett intresse väcks som berikar individen för resten av livet. Betoningen på läsningens estetiska värde fogas därmed in i bildningsidealet. För att kunna deltaga i samhällsdebatten behöver också individen tillgång till de referensramar som förutsätts där och som läsning ger.

Utifrån ett kritiskt perspektiv finns det traditioner i vårt västerländska samhälle som traderar förlegade uppfattningar. I bildningsidealet finns en strävan att lära om, att bryta upp gamla föreställningar och att se världen i ett nytt ljus. Postkoloniala texter och teorier passar väl in i detta sammanhang, även om eleverna inte direkt kommer i kontakt med texter som handlar om Europas skeva bild av Orienten (Said 1978) eller hur kolonialismen har påverkat utbildningssystemet (Willinsky 1998), kan läraren utmana eleverna genom tänkvärda citat eller referat att ta ställning till.

\section{Sociala aspekter på språk- och litteraturundervisning}

Sociolingvister menar att alla erfarenheter i en social grupp realiseras i språket. Språket blir därmed en symbol för individens sociala identitet eftersom hon bedöms utifrån sitt tal 
(Kramsch 1998: 3). Kulturella koder manifesteras alltså i språket och verkar för att utesluta dem som inte känner till koderna. Sociala klasser inom en språkgemenskap använder dessa strategier för att skapa grupptillhörighet. Detta stämmer verkligen när det gäller engelskan med sin talrika repertoar av sociolekter, dialekter och regionala varianter. Vid läsningen av litteratur från den engelskspråkiga världen blir det därför viktigt att inte dölja vilka strukturer som ligger bakom texten i fråga och att framhålla att den inte heller är representativ för en hel kultur utan endast är en subjektiv skildring av densamma. Det här är naturligtvis lättare sagt än gjort, men genom noggrant val av texter kan många aspekter illustreras. Fokusering på estetisk läsning ger också eleverna tillgång till förstahandsupplevelser som kan ge starka incitament att deltaga i gemensamma diskussioner. Maktstrukturer förmedlas inte bara i språket utan också i litteraturen. Vem får bli språkrör för en viss grupp och vem förblir tyst? Detta är en viktig aspekt i postkolonialismen och då främst i studier av de människor som är tystade av olika skäl, s.k. subaltern studies (Spivak 1985:120-130).

Det sociokulturella didaktiska perspektivet fokuserar på det pedagogiska samtalet. Alla samtal utspelas i en social kontext och i skolan är det till stor del läraren som sätter ramarna för hur man beter sig i klassrummet och även hur samtal mellan eleverna ska gå till. Rosenblatt diskuterar lärarens viktiga roll för att alla ska få komma till tals i diskussioner om litteratur. Även Parkinson och Reid Thomas betonar lärarens roll för utvecklandet av ett kommunikationsbefrämjande klassrumsklimat. De menar att läraren redan från början bör etablera vissa grundläggande förutsättningar för litteratursamtal. Parkinson och Reid Thomas föreslår följande regler: att det är frivilligt att uttrycka tankar, att det är accepterat att ogilla texter, samt att det går bra att senare ändra sina åsikter eller tolkningar (Parkinson \& Reid Thomas 2000: 78).

Med tanke på den anda av samförstånd som åtminstone alltsedan Saltsjöbadsavtalen 1938 brukar sägas prägla svenska kommunikationsmönster kan det eventuellt kännas hotfullt att låta olika åsikter brottas med varandra i klassrummet. Men i analogi med Freires frigörande pedagogik är det just i konfrontationen som förändring kan ske och eftersom det inte finns några krav på att problem ska få sin lösning undviker man förhoppningsvis prestige och innehållslösa, politiskt korrekta åsikter (Freire 1970).

Vissa känsliga frågor och åsikter kan vara alltför privata för att eleven ska vilja ta upp dem i klassrumsdiskussionen och därför kan det vara lämpligt att erbjuda andra

kommunikationssätt, t.ex. läsloggar med korta betraktelser eller reflektioner som uppstått under läsningen och som bara läraren läser. Eleverna kan ha ett starkt behov av att uttrycka även mer privata känslor och tankar (Smith 1995: 124).

\section{Läsningens funktion}

Jag har redan genom referenser till läro- och kursplaner motiverat litteraturens plats i språkundervisningen, men vilka andra roller kan litteraturen spela? Historiskt sett har litteraturen haft till uppgift att underhålla och väcka tankar samt, åtminstone fram till 1700talet, förmedla moraliska budskap. Numera betraktas väl sådana tendenser med skepsis, även om t.ex. politisk teater skulle kunna benämnas moraliserande (Parkinson \& Reid Thomas 2002: 24).

En intressant fråga är hur läsarens syften påverkar läsningen. Rosenblatt lanserade redan 1938 begreppen efferent respektive estetisk läsning, vilket anger på vilket sätt läsaren närmar sig texten. I en estetisk läsning är det läsglädje och läsupplevelse som står i centrum, medan den efferenta läsningen innebär ett mer analytiskt och informationssökande förhållningssätt. Varför man läser påverkar alltså den läsart man väljer (Rosenblatt 1995: 32).

Rosenblatt ser läsning som en transaktion mellan text och läsare. I transaktionen är läsaren aktiv och läser på olika sätt beroende på var hon befinner sig i livet och vilka behov hon har just då. Läsaren kan t.ex. ha behov av en känslomässig ventil, starka upplevelser, 
kunskap om fjärran platser och andra människor, erfarenhet av farliga äventyr, möjlighet att få utlopp för undertryckta drifter samt tillfälle att erfara känslor av upprymdhet och meningsfullhet. För yngre läsare är det nyfikenhet på livet som är främsta drivkraften i läsandet, framhåller Rosenblatt. Genom att läsa utforskar ungdomar sig själva och världen omkring dem och litterära verk kan hjälpa dem se meningsfulla strukturer och sammanhang i tillvaron (Rosenblatt 1995: 36-42).

Charles Sarland visar också på läsningens funktion i sin bok Young People Reading (1991). Han menar i likhet med Rosenblatt att ungdomars största motivation i läsningen är att hitta karaktärer att identifiera sig med, att upptäcka sin egen värld och få kännedom om fenomen som de vuxna talar tyst om. Sarland finner att eleverna får starkare läsupplevelser av populärkulturella böcker eftersom de är skrivna på vardagsspråk och innehåller typiska situationer och karaktärer, som det går lätt att identifiera sig med (Sarland 1991: 73-7). Bruce E. Fleming betonar läsningens meningsskapande funktion, att vi lär oss vad det innebär att vara människa. När vi ser våra egna känslor och tankar i tryck blir vi bekräftade och ser oss själva med andra ögon. Fleming understryker läsningens förmåga att inte bara ge oss kunskap utan också förändra hur vi ser på världen eftersom litteratur alltid presenterar ett urval av händelser och känslor och tydliggör dolda strukturer (Fleming 2002: 471).

Om det är viktigt för motivationen att man finner sig själv i texten kan detta bli ett problem med texter som har uppbruten kronologi och som lämnar mycket till läsaren. Det är då betydelsefullt att eleverna får diskutera vilken funktion dessa texter har och varför den postmoderna formen kan ha valts. Läraren kan också engagera eleverna på olika sätt så att de hittar vägar in i texten. Detta kan göras genom att man dramatiserar en sekvens i boken eller fantiserar vidare kring en karaktärs bakgrund, men även genom efterforskningar om tidsepoken eller kulturella faktorer. Det är dock viktigt att man låter eleverna möta texten på deras egna villkor, så att de får möjlighet att njuta av läsningen (estetisk läsning), utan att skriva dem på näsan hur de ska tolka texten (Rosenblatt 1995: 58-9). Det är intressant att notera i detta sammanhang att det ofta tas för givet att elever ska kunna upptäcka universala budskap i kanoniska texter, medan andra texter inte förväntas erbjuda samma möjlighet. Men eleverna kanske tycker det är lika svårt att läsa en text från 1800-talets England som en nutida text från Sydafrika.

\section{Val av texter}

För att gå vidare till den konkreta pedagogiska praktiken kan texturvalet orsaka vissa svårigheter för lärare. Inte nog med att eleverna är på olika mognads- och kunskapsnivå, de har också olika preferenser och tidigare erfarenheter av litteraturläsning i skolan, vilket påverkar deras inställning. Andra faktorer som begränsar valet kan vara vilka texter som finns tillgängliga på skolan eller lärarens egna intressen. Catherine Wallace intar en freiriansk utgångspunkt till val av texter (se Freire 1970). Hon menar att man ska välja texter som har ett kontroversiellt innehåll eftersom litteraturundervisningen bör koncentreras på att hitta och diskutera problem i texter, alltså inte på att lösa dem. Man kan också välja texter som behandlar samma problem från olika perspektiv för att medvetandegöra eleverna om texters subjektivitet (Wallace 1992: 103-9).

Bo Lundahl räknar upp en mängd variabler som kan influera texturvalet i Läsa på främmande språk (1998) där han också förespråkar användandet av autentiska texter i språkundervisningen. När det gäller texturvalet tar Lundahl upp frågor som rör graden av intressant innehåll, identifikationspotential för eleven, åldersanpassning, attraktiv layout, anknytning till kursplanen, kulturella skillnader, språklig nivå, genre etc. (Lundahl 1998: 83).

Alla textval påverkas också av normativa aspekter på litteratur och här syftar jag främst på relationen till den litterära kanon. I kursplanen står att eleven ska "ha grundläggande orientering om engelskspråkig litteratur från olika epoker" (Skolverket, 2000b), vilket ger lärare i Sverige mer frihet än deras kollegor i t.ex. USA eller Storbritannien har. 
Värderingar på vad som är god respektive dålig litteratur kan också ge upphov till intressanta diskussioner i klassen. Man kan t.ex. diskutera varför inkluderandet av kvinnliga eller postkoloniala författare i kanon för det första behövs och för det andra vilka ideologiska och historiska faktorer som har utestängt dessa och många andra grupper tidigare. Med ett problematiserande tillvägagångssätt i litteraturundervisningen finns en chans att bakomliggande maktstrukturer kan undersökas. Valet av litterära texter kan därför inte bli neutralt och återigen blir identitet och grupptillhörighet viktiga i ett maktperspektiv. Genom en historisk tillbakablick kan man titta på hur traderingen av litterära texter gått till och hur detta hängt ihop med imperialism och nationalism (Willinsky 1998: 216-23).

Syftet med diskussioner som dem jag har refererat till ovan är också viktigt. Blir det en undervisning om litteratur eller blir det undervisning som berikar läsupplevelsen och får eleverna att förhålla sig kritiska, i en positiv bemärkelse, till varför vissa texter läses men inte andra?

Baserad på en litteraturvetenskaplig analys av fem postkoloniala texter samt en genomgång av didaktiska och litteraturvetenskapliga teorier har jag i min magistranduppsats ställt upp några enkla kriterier för att underlätta valet av texter utifrån ett värdegrundsperspektiv:

1. Innehåller texten element som kan kopplas till värdegrundsfrågor?

2. Är texten intressant att läsa och diskutera?

3. Ligger texten på en passande språklig nivå?

4. Inbjuder den till olika tolkningar?

5. Är det en postkolonial text? (Thyberg 2002: 4, 25-6)

För en utförlig motivering av kriterierna hänvisar jag till uppsatsen. Dock vill jag återigen understryka att eleverna bör inkluderas i urvalsprocessen för att få med värdegrundsfrågorna i arbetssättet. Upplever eleverna delaktighet i beslut som rör undervisningen blir kanske deras motivation att aktivt deltaga högre.

\section{Problem med litteraturundervisning i skolan}

Redan 1938 beklagade Rosenblatt att litteraturundervisningen i skolan tyvärr ofta tar död på elevernas läsintresse. De får uppfattningen att det gäller att läsa på ett förutbestämt sätt för att hitta vissa element och strukturer i texten samt att återge referenslitteraturens resonemang. Eleverna lär sig om litteratur i stället för att lära sig att uppleva och tolka litteratur. Hon anser alltså att det är elevernas egna upplevelser av litteraturen som borde komma i första hand. Tyvärr sätter ofta examinationskravet käppar i hjulet för denna inriktning på undervisningen (Rosenblatt 1995: 57). Därför är det än viktigare att konstruera examinationsfrågor på ett sådant sätt att eleverna inte reducerar inlärningen till sådan ytkunskap som biografiska fakta eller kända tolkningar (Hounsell m.fl. 1986: 28). Variation av uppgifter och arbetssätt är säkert också viktigt för att behålla läsglädjen hos eleverna.

Ett annat problem är skillnaderna mellan lärarens och elevernas läsarreception. Rosenblatt menar att alla läsare bär med sig unika erfarenheter och minnen till läsningen och att detta avgör vilka aspekter i texten som läsarna uppfattar. Detta kan sägas vara ett av de första uttalanden inom det som senare har blivit kallat receptionsforskning. I klassrumssituationen kan följden bli att läraren väntar sig att eleverna ska uppmärksamma vissa aspekter i en text och lägger upp arbetet utifrån detta, medan eleverna kan ha fastnat för och vilja diskutera helt andra företeelser (Rosenblatt 1995: 59).

Detta resonemang har hittills gällt läsning av skönlitteratur rent allmänt, men hur är det med läsningen inom engelskämnet? Jo, då kan det delvis vara andra aspekter som är problematiska och som hänger ihop med själva språkinlärningssituationen. Det handlar bland annat om hur eleverna påverkas av olika arbetssätt. Förändras elevernas läsning när de får i uppgift att läsa vissa avsnitt intensivt där alla ord måste slås upp och sättas upp i en ordlista? Eller hindrar kanske bristande språkkunskaper full upplevelse eller förståelse av boken? En del elever kan ha ett starkt inre motstånd mot att läsa på engelska eftersom de 
tror att det måste vara för svårt. Det kan också förhålla sig som Rosenblatt misstänker, att lärare slentrianmässigt, och kanske omedvetet, tvingar eleverna att läsa ytinriktat efter vissa uttalade eller underförstådda krav. Behandlar man alla böcker efter samma modell så att eleverna på förhand vet vad de ska leta efter i texterna, s.k. efferent läsning? Redovisas läsningen främst för läraren eller är syftet snarare att sprida kunskapen till andra i klassen? Diskuteras målet med läsningen i klassen och är syftet då att lära sig ord eller att läsa böcker man tycker om?

Dessa pedagogiska val påverkar utan tvivel elevernas sätt att läsa. Frågan är förstås hur beroende uppfyllandet av läroplans- och kursplansmålen är av dessa metodiska skillnader. Men de allra mest intressanta aspekterna i mina ögon är hur eleverna själva resonerar kring läsningen av skönlitteratur på engelska, hur de upplever läsningen och hur de ser på kulturmötet i texterna. Det är detta jag vill undersöka i mitt kommande avhandlingsarbete.

\section{Avslutning}

Jag har här försökt att visa på en möjlig koppling mellan värdegrundsfrågor och främst Bkursen i engelska på gymnasienivå. För en mer utförlig genomgång och för konkreta metodiska förslag för undervisningskontexten hänvisar jag läsaren till min magistranduppsats. Enligt det resonemang som förts i denna artikel tycks det ändå möjligt att värdegrundsfrågor skulle kunna integreras i engelskundervisningen på två sätt, dels genom ett demokratiskt arbetssätt med samtalet i fokus, dels genom litteraturläsning med kulturmöten i centrum. Jag har också framhållit läsningens estetiska värde med fokus på elevens läsglädje och rätt att läsa utefter sina förutsättningar och behov.

\section{(C) Anna Thyberg}

\section{Litteraturlista}

Ashcroft, B., Griffiths, G, \& Tiffin, H. (red.) 1995: The Post-colonial Studies Reader. London \& New York: Routledge.

Fleming, B. E. 2000: What is the Value of Literary Studies? I New Literary History, vol 31, s. 459-76.

Freire, P. 1970: Pedagogy of the Oppressed. New York: Seabury.

Fritzell, C. 1996: Pedagogical Split Vision. I Educational Theory, vol. 46, s. 203-216. Gudykunst, W. \& Kim, Y. Y. 1992: Communication with Strangers: An Approach to Intercultural Communication. New York: McGraw-Hill.

Hounsell, D., Carlsson, M. A., Entwistle, N. \& Marton, F. 1986: Hur vi lär. Stockholm: Rabén \& Sjögren.

Kramsch, C. J. 1998: Language and Culture. Oxford: Oxford Univ. Press.

Lundahl, B. 1998: Läsa på främmande språk : om autentiska texter, kreativ läsning och läsförmågans betydelse för språkinlärningen. Lund: Studentlitteratur.

Parkinson, B. \& Reid Thomas, H. 2000: Teaching Literature in a Second Language. Edinburgh: Edinburgh University Press.

Rosenblatt, L. M. 1938, 1995 (5:e utg.): Literature as Exploration. New York: The Modern Language Association of America.

Said, E. W. 1978: Orientalism. London \& Henley: Routledge \& Kegan Paul.

Sarland, C. 1991: Young People Reading : Culture and Response. Milton Keynes: Open Univ. Press.

Skollagen 1985: Tillgänglig för nedladdning på http://www.riksdagen.se/debatt/sfst/ Sök på SFS nr: 1985:1100. Nedladdad 2003-03-20.

Skolverket 1994: Läroplan för de frivilliga skolformerna. Tillgänglig för nedladdning på http://www.skolverket.se/pdf/lpf94.pdf. Nedladdad 2003-03-20.

Skolverket 2000a: Kursplanen för engelska. Tillgänglig för nedladdning på http://www3.skolverket.se/ki/SV/0203/sf/21/ol/index.html. Nedladdad 2003-03-24.

Skolverket 2000b: Kursplanen för engelska B. Tillgänglig för nedladdning på http://www3.skolverket.se/ki/SV/0203/sf/21/ol/index.html. Nedladdad 2003-03-20 
Smith, S. E. 1995:"Please Correct Me If I Am Wrong": Teaching Civil Rights and Race Relations in the Age of the Politically Correct. I Goebel, B. A. \& Hall, J.C. (red.) Teaching a "New Canon"? Urbana: National Council of Teachers of English.

Spivak, G. C. 1985: Can the Subaltern Speak? Speculations on Widow-Sacrifice. Wedge, Winter/Spring, s. 120-130.

Thyberg, A. 2002: Literature and Civic Values in the English Classroom. Växjö universitet.

Wallace, C. 1992: Reading. Oxford: Oxford Univ. Press.

Willinsky, J. 1998: Learning to Divide the World: Education at Empire's End.

Minneapolis: University of Minnesota Press. 